\title{
Short-Term Results of Vagal Nerve Stimulation in Resistant Epilepsy Patients
}

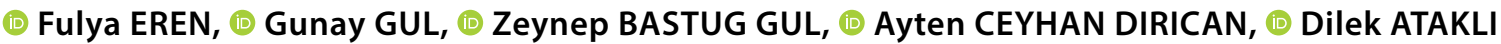

Departments of Neurology, University of Health Sciences, Bakırköy Prof. Dr. Mazhar Osman Mental Health and Neurology Training and Research Hospital, İstanbul, Turkey

\begin{abstract}
Objectives: Vagal nerve stimulation (VNS) is an appropriate treatment option for refractory patients who are not eligible for resective epilepsy surgery. In this study, the clinical and demographic characteristics of VNS patients were documented and it was aimed to determine the effect of VNS on seizure control.

Methods: A retrospective survey was performed for patients who were diagnosed as drug resistant epilepsy and underwent VNS implantation, with at least 1 year of follow-up. Nine patients (eight males and one female) with an average age of 30.11 (18-42), were included. Reduction in seizure frequency prior and in the $3^{\text {rd }}, 6^{\text {th }}$, and $12^{\text {th }}$ months after VNS implantation was compared. Patients were considered responders when a reduction of seizures of more than $50 \%$ was reported.

Results: The mean time from the onset of the disease to VNS implantation was $17.33 \pm 9.75$ years and the mean age when VNS was implanted was 24.53 (9-39). Decrease in frequency of seizures from VNS implantation to 3 months and 6 months was statistically significant ( $p=0.003$ and $p=0.012$, respectively). No statistical significance was found between the frequency of seizures before treatment and at the 12 th month $(p=0.153)$.

Conclusion: In our study, we observed a decrease in seizure frequency in patients with drug resistant epilepsy with a variety of etiologies, which was similar with the literature data. Although a cumulative effect was reported, we have observed a minimal decrease in frequency after the $3^{\text {rd }}$ month.
\end{abstract}

Keywords: Drug-rezistant epilepsy; epilepsy; vagal nerve stimulation.

Cite this article as: Eren F, Gul G, Bastug Gul Z, Ceyhan Dirican A, Atakli D. Short-Term Results of Vagal Nerve Stimulation in Resistant Epilepsy Patients. Epilepsi 2021;27:138-143.

\section{Giriş}

Epilepsi nöroloji pratiğinde en sık görülen hastalıklardan biridir. Toplumda \%0.5-1 arasında gözlenir. İki farklı uygun tolere edilebilen ilacı, uygun dozda kullanmasına rağmen nöbetleri devam eden hastalar Uluslararası Epilepsi ile Savaş Derneği (ILAE) tarafından dirençli epilepsi olarak tanımlanmaktadır. ${ }^{[1,2]}$ Epilepsi hastalarının yaklaşık 1/3'ünün bu tanımlamaya göre dirençli epilepsi olarak seyrettiği bilinmektedir. ${ }^{[2]}$ Dirençli epilepsi hastalarında rezektif cerrahi

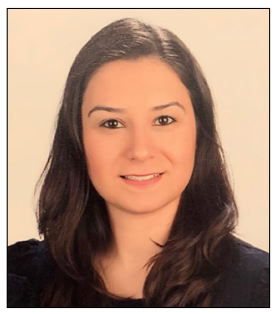

Corresponding author Fulya EREN, M.D.

e-mail fulyasengul@yahoo.com

Received 21.02.2021

Accepted 12.04.2021

Online date 30.07.2021

Content of this journal is licensed under a Creative Commons Attribution-NonCommercial 4.0 International License.

Fulya EREN, M.D.

C 2021 Turkish Epilepsy Society tedavi en sık uygulanan yöntemdir. Ancak multifokal nöbet başlangıçları olan, epileptik zonu kritik kortikal alanlara yakın olan hastalar ile cerrahi sonrası nöbetleri devam eden bu nedenlerle rezektif cerrahiye aday olmayan hastalar için vagal sinir stimulasyonu (VNS) en sık uygulanan nörostimulasyon yöntemidir. Nöbet sıklığında azalma yarattığı yapılan bazı çalışmalarda da desteklenmiştir. ${ }^{[3,4]}$ VNS kullanımı, ilk olarak 1997 yılında Amerikan Gıda ve İlaç Dairesi (FDA) tarafından cerrahiye uygun olmayan, 12 yaş üstü dirençli epilepsi hastalarının tedavisinde onaylanmıştır. ${ }^{[5]}$ Fokal başlayan nöbetlerde kullanılabileceği gibi, fokal başlayıp bilateral tonik-klonik nöbete ilerleyen ve dirençli jeneralize nöbetleri olan hastaların tedavisinde de kullanılmaktadır. Ülkemizde de 2009 yılında Sosyal Güvenlik Kurumu'nun belirlediği prosedürler ışığında uygun epilepsi merkezlerinde kullanılan bir tedavi seçeneğidir. ${ }^{[6]}$

VNS, sol subklavian bölgeye cilt altına yerleştirilen bir jeneratör ve sol vagus siniri çevresine yerleştirilen stimulan elektrotlardan oluşmaktadır. 3 farklı şekilde stimulasyon yapmaktadır: 


\section{Dirençli Epilepsi Hastalarında Vagal Sinir Stimulasyonunun Kısa Dönem Sonuçları}

\section{$\ddot{0} z$}

Amaç: Epilepsi hastaların 1/3'ünün politerapiye rağmen ilaca dirençli olduğu bilinmektedir. Vagal sinir stimulasyonu (VNS) rezektif epilepsi cerrahisine uygun olmayan dirençli hastalarda uygun bir tedavi seçeneğidir. Bu çalışmada, VNS hastalarının klinik ve demografik özellikleri dökümente edilmiş ve VNS'in nöbet kontrolündeki etkisinin belirlenmesi amaçlanmıştır.

Gereç ve Yöntem: Hastanemiz epilepsi polikliniğinden VNS implantasyonu sonrası en az 1 yıldır takip edilen, dirençli epilepsi hastalarının verileri retrospektif olarak değerlendirildi. Çalışmaya ortalama yaşı 27.50 (11-42) olan 14 hasta (11 erkek, 3 kadın) dahil edildi.Hastaların demografik dataları, epilepsi etyolojileri, nöbet sıklıkları, nöbet tipleri, kullandıkları ilaçlar dökümente edildi. VNS öncesi ile 3, 6 ve 12. aylardaki nöbet sıkları kıyaslandı. Nöbet sıklığındaki $\geq \% 50$ azalma anlamlı kabul edildi.

Bulgular: Hastalığın başlangııından VNS implantasyonuna kadar geçen süre ortalama 17.33 \pm 9.75 yıl, VNS takıldığındaki yaş ortalaması 24.53 (9-39) idi. VNS implantasyonundan sonra geçen süre ise ortalama 4.69 \pm 3.72 yıl olarak tespit edildi. VNS implantasyonu öncesi hastaların ortalama nöbet sıklıkları 92.8 \$97.33/ay olarak gözlendi. Tedavi sonrası 3. ay takiplerinde 9 hastanın, 6 . ayda 7 hastanın, 12 ayda ise 7 hastanın nöbet sıklığında tedavi öncesine göre $\% 50$ ve üzeri azalma tespit edildi. Hastaların 0 ile 3. ay nöbet sıklıkları ve 0 ile 6 . ay nöbet sıklıkları değerlendirildiğinde nöbet sıklığındaki azalma, istatistiksel olarak anlamlı bulunmuştur (sırasıyla; $p=0.003, p=0.012$ ). Tedavi öncesi ile 12. ay bakıldığında ise nöbet sıklıkları arasında istatistiksel anlamlılık bulunamamıştır $(p=0.153)$.

Sonuç: Çalışmamızda literatür ile uyumlu olarak VNS dirençli hastalarda nöbet sıklığını azalttığı gözlenmiştir. Kümülatif bir etkisi olduğu bazı çalışmalarda gösterilmişse de bizim çalışmamızda 6. aydan itibaren bir değişiklik saptanmıştır.

Anahtar sözcükler: Dirençli epilepsi; epilepsi; nörostimulasyon; vagal sinir stimulasyonu.

1. Temel (base-line) stimulasyon

2. Hastanın kendinin uyguladığı magnet stimulasyonu

3. Bazı modellerde olan iktal taşikardiye duyarlı otostimulasyon. ${ }^{[3]}$

Etki mekanizması halen net olarak anlaşılamamak ile birlikte kortikal ve subkortikal etkileri olduğu düşünülmektedir. Noradrenalin, serotonin ve gama-aminobütirik asit (GABA) üzerinden etkili olduğunu öne süren görüşler vardır. VNS tedavisi sonrası hastaların beyin omurilik sıvılarında serotonin aktivitesi markerı 5-hidroksiindolasetik asit (5-HIAA) ve GABA düzeylerinin arttığı gözlenmiştir. ${ }^{[7]}$ Ayrıca hastaların kan tetkiklerinde tespit edilen yüksek sitokin değerleri ve belirgin antienflamatuar yanıt, enflamatuar süreçlerde bir modulasyon olabileceğini de desteklemektedir. ${ }^{[8]}$

Bu çalışmada medikal tedaviye dirençli olan ve VNS tedavisi altındaki hastaların klinik, demografik özelliklerinin gözden geçirilmesi, tedavi ile nöbet sıklıklarının ve tedavi başarısının üzerine etkili olan faktörlerin değerlendirilmesi amaçlanmıştır.

\section{Gereç ve Yöntem}

Hastanemiz epilepsi polikliğinden 2010-2019 yılları arasında dirençli epilepsi tanısı ile takip edilen ve VNS implantasyonu yapılan, en az 1 yıllık takiplerine ulaşılabilen hastalar çalışmaya dahil edildi. Çalışmaya alınan tüm hastaların VNS implantasyonu öncesi non-invazif incelemeleri (manyetik rezonans (MR), elektroensefalografi (EEG), positron emisyon tomografisi (PET), nöropsikometrik inceleme) yapılmış ve rezektif cerrahiye aday olmadıklarına karar verilmişti.
Hastaların geriye dönük olarak sosyodemografik özellikleri, hastalık süreleri, EEG, MR bulguları, ILAE 2017 sınıflamasına göre nöbet tipleri, epilepsi etiyolojileri, kullandıkları ilaçlar, tedavi öncesi ve sonrası hastaların tuttukları nöbet günlüklerine göre kaydedilen, 3., 6. ve 12. ay nöbet sıklıkları geriye dönük olarak dökümente edildi.

Tedavi öncesine göre nöbet sıklıklarında \%50 ve üzeri azalma saptanan hastalar tedaviye yanıtlı olarak değerlendirildi. Ayrıca hastaların tedavi sonrası nöbet sıklıkları değerlendirilirken Mc Hugh sınıflaması kullanıldı.. ${ }^{[9]}$ Bu sınıflandırmada; hastalar nöbet sıklıklarındaki azalma yüzdesine göre beş sınıfa ayrıldı. \%80-100 arasında nöbet sıklığında azalma olanlar sınıf 1, \%50-79 arasında nöbet sıklığında azalma olanlar sınıf 2, \%50'den az nöbet sıklığında azalma olanlar sınıf 3, sadece mıknatıs yararı (magnet benefit) olanlar sınıf 4 ve iyileşme göstermeyen hastalar sınıf 5 olarak değerlendirilmektedir. Illk 3 sınıf ayrıca iktal ve postiktal aktivitede gelişme olup olmamasına göre A ve B olarak 2 alt gruba ayrılmaktadır. Sınıf 1 ve 2 tedaviye iyi yanıtlı, sınıf 3, 4 ve 5 kötü yanıtlı olarak kabul edildi. Hastaların VNS implantasyonu sırasındaki hastalık süreleri, nöbet tipleri, MR bulguları ile 3., 6. ve 12. aydaki nöbet sıklıkları karşılaştırıldı ve nöbet sıklıklarındaki \% değişimleri değerlendirildi.

Teknik bilgi- Hastaların nöbet sıklığına göre output'ları ve stimulasyon amplitüdleri, bir nöroloji uzmanı gözleminde 0.25-0.5 miliamper ( $\mathrm{mA}$ ) artışlarla kademeli yükseltilmişti. Hastaların output değerleri 0.75-3 mA, stimulasyon amplitüdleri ise $1.25-3 \mathrm{~mA}$ değerleri arasındaydı. Stimulasyon frekansı 30 Hertz $(\mathrm{Hz})$ idi. 
İstatistiksel analiz- $\mathrm{Bu}$ çalışmadaki istatistiksel analizler SPSS (version 26, IBM, New York, USA) programı kullanılarak yapılmıştır. Tanımlayıcı istatistik metodlar (normal dağılımda ortalama ve standart sapma, normal olmayan dağılımda median ve interquartil değerleri) verileri raporlarken kullanılmıştır. Tedavi öncesi ve sonrası nöbet sıklıkları değerlendirilirken Wilcoxon Sign-Rank test kullanılmıştır. Hastalık süresi ile nöbet sıklığı arasındaki ilişkiyi ortaya koymak için bağımsız t-test kullanılmıştır. Nöbet tiplerine göre

Tablo 1. Hastaların sosyodemografik ve klinik özellikleri

\begin{tabular}{lc}
\hline Hasta sayısı & 14 \\
Erkek & 11 \\
Kadın & 3 \\
Yaş & $27.50(11-42)$ \\
VNS takılma yaşı & $24.53(9-39)$ \\
VNS takıldığında hastalık süresi & $17.33 \pm 9.75$ yıl \\
VNS altında takip süresi & $4.69 \pm 3.72$ yıl \\
Antiepileptik sayısı & \\
2 ilaç & 1 hasta \\
3 ilaç & 5 hasta \\
4 ilaç & 8 hasta \\
Nöbet sayısı (nöbet/ay) & $92.8 \pm 97.33$ \\
\hline
\end{tabular}

Tablo 2. Hastaların nöbet tipleri ve nöbet etiyolojileri

\begin{tabular}{ll}
\hline & Hasta sayısı \\
\hline Nöbet tipi & 7 \\
$\quad$ Fokal & 6 \\
$\quad$ Fokal+bilateral tonik - klonik & 1 \\
$\quad$ Jeneralize & \\
Nöbet etiyolojileri & 4 \\
$\quad$ Sekel lezyonla ilişkili semptomatik & \\
(ensefalomalazi/iskemi) & \\
Nedeni bilinmeyen & 4 \\
Tuberoz Skleroz & 2 \\
Kortikal malformasyon & 2 \\
Myoklonik astatik epilepsi & 1 \\
Adrenolökodistrofi & 1 \\
\hline
\end{tabular}

Tablo 4. On ikinci ayda Mc Hugh sınıflamasına göre hasta dağılımları

\begin{tabular}{|c|c|c|c|c|c|c|c|c|}
\hline Mc Hugh sınıflaması & $1 a$ & $1 b$ & $2 a$ & $2 b$ & $3 a$ & $3 b$ & 4 & 5 \\
\hline Hasta sayısı & 3 & 1 & 2 & 1 & 2 & - & - & 5 \\
\hline Hasta yüzdesi & & $\%$ & 50 & & & $\% 5$ & & \\
\hline
\end{tabular}

$\%$ azalma oranları ki-kare testi ile, yaş ile \% azalma oranları ise Kruskal-Wallis metodu ile değerlendirilmiştir. Bu çalışmada $\mathrm{p}<0.05$ değeri istatistiksel olarak anlamlı olarak kabul edilmiştir.

\section{Bulgular}

Çalışmaya 3 kadın 11 erkek olmak üzere 14 hasta dahil edildi. Hastaların yaş ortalaması 27.50 (11-42), ortalama hastalık süresi $22 \pm 10.4$ yıl olarak tespit edildi. Farklı epilepsi etiyolojilerine sahip hastaların 7'sinin fokal epileptik nöbetleri var iken, 6 hastanın nöbetleri fokal başlayan nöbetlerin yanısıra fokal başlayan ve bilateral tonik-klonik nöbetlere ilerleyen nöbetler şeklinde idi. 1 hasta ise jeneralize epileptik nöbet geçirmekteydi. 4 hastanın kranial MR'ında herhangi bir patoloji saptanmazken, diğer 10 hastanın görüntülemelerinde çeşitli özellikler saptandı. Tüm hastalar medikal tedaviye dirençli olup, 2 veya daha fazla antiepileptik ilacın kombinasyonlarını kullanmaktaydı. Hastalığın başlangıcından VNS implantasyonuna kadar geçen süre ortalama 17.33 \pm 9.75 yıl, VNS takıldığındaki yaş ortalaması 24.53 (9-39) idi. VNS implantasyonundan sonra geçen süre ise ortalama $4.69 \pm 3.72 \mathrm{yll}$ olarak tespit edildi (Tablo 1 ve 2 ).

VNS implantasyonu öncesi hastaların ortalama nöbet sıklıkları 92.8土97.33/ay olarak gözlendi. Tedavi sonrası 3. ay takiplerinde 9 hastanın, 6 . ayda 7 hastanın, 12 ayda ise 7 hastanın nöbet sıklığında tedavi öncesine göre $\% 50$ ve üzeri azalma tespit edildi. Hastaların 0 ile 3. ay nöbet sıklıkları ve 0 ile 6 . ay nöbet sıklıkları değerlendirildiğinde nöbet sıklığındaki azalma, istatistiksel olarak anlamlı bulunmuştur (sırasıyla; $p=0.003, p=0.012$ ). Tedavi öncesi ile 12 . ay bakıldığında ise nöbet sıklıkları arasında istatistiksel anlamlılık bulunamamıştır ( $p=0.153$ ) (Tablo 3). Hastalar VNS sonrası Mc Hugh sı-

Tablo 3. Aylara göre höbet sıklıkları karşılaştırılması

\begin{tabular}{lcccc}
\hline Ay & Medyan (IQR) & $\mathrm{p}^{*}$ & $\begin{array}{c}\text { İyi cevaplı hasta sayısı } \\
\text { (\%50 ve üzeri nöbet azalması) }\end{array}$ & $\begin{array}{c}\text { Kötü cevaplı hasta sayısı } \\
\text { (\%50 ve altında nöbet azalması) }\end{array}$ \\
\hline 3 & $40(16-165)$ & 0.003 & 9 & 5 \\
6 & $22.5(4.5-112.5)$ & 0.012 & 7 & 7 \\
12 & $75(6.75-120)$ & 0.153 & 7 & 7 \\
\hline
\end{tabular}

IQR: Interquartil aralık. "Wilcoxin sign rank test. 
nıflamasına göre de sınıflanmıştır. \%50 ve üzeri nöbet azalması olan iyi cevaplı grupta (sınıf 1-2) 7 hasta varken, \%50 ve altında nöbet azalması olan kötü cevaplı grupta ise (sınıf 3-4) 2 hasta, iyileşme göstermeyen ise 5 hasta olduğu tespit edilmiştir (Tablo 4). Hastaların tamamında VNS implantasyonu sonrasında, özellikle uyarım değerleri arttırılırken kısa süreli ses kısıklığı ve öksürük yan etkisi gözlenmiş ancak bu etkiler tedaviyi aksatacak düzeyde olmamıştır.

Hastalar, VNS implantasyonuna kadarki hastalık süresi ile 3. ay, 6. ay ve 12. ay \% nöbet azalması aylara göre incelendiğinde, hastalık süresinin nöbet azalması üzerine anlamlı ilişkisi gösterilememiştir (sırasıyla; $p=0.743, p=0.118, p=0.277$ ). İyi ve kötü cevaplı hastalar aylara göre, nöbet tipine göre değerlendirildiğinde yine anlamlı bir ilişki izlenmemiştir (sırasıyla; $p=0.717, p=0.788, p=0.214$ ).

VNS implantasyon sırasındaki yaş ile $\% 50$ üzeri ve altı cevaplılık kıyaslandığında 3 . ay, 6 . ay ve 12 . ay verilerinde istatistiksel olarak anlamlılık tespit edilmemiştir (sırasıyla; $p=0.601$, $\mathrm{p}=0.181, \mathrm{p}=0.140$ ).

\section{Tartışma}

VNS, 20 yılı aşkın bir süredir dirençli epilepsi tedavisinde bir seçenek olarak yer almaktadır. Dirençli epilpsi tanısı alıp rezektif cerrahiye aday olmayan ya da rezektif cerrahi sonrası nöbetleri devam eden hastalarda nöbet sıklığı ve yaşam kalitesi üzerine olumlu etkisi olduğu düşünülmektedir. VNS 'in nöbet sıklığı üzerine olan etkisini farklı oranda olduğunu söyleyen çalışmalar bulunmaktadır. Hastaların \%23.4-63.8'inde nöbet sıklığında \%50 ve üzeri azalma olduğu söylenebilmektedir. ${ }^{[10-12]}$ Yapılan meta-analizlerde 3-12 ay arasında nöbet sıklığında tedavi sonrası ortalama \%36 azalma olduğu, 1 yıldan sonra ise bu oranın \%51 olarak değerlendirildiği bildirilmiştir. ${ }^{[13]}$ Başka bir çalışmada da 12, 24 ve 36 . ay takiplerinde $\% 50$ azalmanın oranın takip süresi arttıkça yükseldiği ortaya konmuştur. ${ }^{[14]} \mathrm{Bu}$ çalışmada hastaların toplam nöbet sıklıklarına baktığımızda literatür ile uyumlu olarak, değerlendirilmeye alınan tüm aylarda anlamlı azalma tespit edilmiştir. 3. ayda hastaların \%62'sinin, 6. ve 12. aylarda ise hastaların \%50'sinin tedaviye cevaplı olduğu gözlenmiştir. Bu sonuçların, daha önce belirtildiği gibi yapılan diğer çalışmalardaki değer aralıklarının arasında kaldığı gözlenmiştir. Ancak 3 aydan sonra diğer takiplerinde nöbet kontrolünde artış saptanmamıştır. Ülkemizde yapılan bir çalışmada hastaların \%20'sinin tedaviye cevapsız olduğu bildirilmiştir. Bizim çalışmamızda cevapsız hasta sayısı bu değerin üzerinde olarak \%35.7 olarak bulunmuştur. [15] Bu sonuçların hastaların 1 yıldan daha uzun takiplerinin değerlendirilmemiş olması ve örneklem küçüklüğü ile ilgili olduğu düşünülmektedir.
İlk olarak fokal başlangıçlı epilepsisi olan hastalarda ekleme tedavisinde etkili olduğu düşünülmekle beraber jeneralize nöbetleri olan hastalarda da olumlu etkileri olduğu gösterilmiştir. Englot ve arkadaşları parsiyel başlangıçlı nöbetleri olan hastalarda daha iyi sonuçlar elde etmişlerdir. ${ }^{[16]}$ Ancak bilgi birikiminin artması ile günümüzde tüm nöbet tiplerine ve farklı etiyolojilerdeki hastalarda etkili olduğu gösterilmiştir. ${ }^{[17]}$ Özellikle farklı etiyolojilere bağlı olarak multifokal iktal fokusu olan hastalar ile dirençli idiyopatik jeneralize epilepsiler de VNS endikasyonlarıdır. ${ }^{[10]}$ Bu çalışmada farklı nöbet tipleri ve etiyolojileri olan hastalar değerlendirilmiştir. Literatür ile uyumlu olarak nöbet tipleri ile VNS sonrası nöbet sıklıkları arasında ilişki bulunmamıştır.

Yapılan çalışmalarda VNS tedavisinin nöbet sıklığı üzerine etkisini ön gören faktörler belirlenememiştir. Çocuk hastalar üzerinde yapılan çalışmalarda 12 yaş ve üzeri hastalar kıyaslandığında VNS etkisi ve güvenliği açısından anlamlı fark saptanmamıştır. Çocuk hastalarda da yetişkinlerle eş değer etkiler gösterilmiştir. ${ }^{[11,18]}$ Ancak 18 yaşından küçük olanlarda daha iyi nöbet kontrolü sağlandığını söyleyen çalışmalar da bulunmaktadır. ${ }^{[16]}$ Bizim çalışmamızda hastaların VNS implantasyon yaşı ile nöbet sıklıkları değerlendirildiğinde yaşın prognoz üzerine anlamlı bir etkisi olduğu gösterilememiştir.

Hastalık süresinin uzun olması, kullanılan antiepileptik ilaçlara maruziyet, nöbetlere bağlı yaralanmalar, kognitif etkilenme ile ilişkili olarak hastaların yaşam kalitesini olumsuz etkileyebilmektedir. Hastalar, VNS implantasyonu sırasındaki hastalık süresi açısından değerlendirildiğinde 10 yıldan daha az süredir nöbetleri olan hastaların daha iyi sonuçlara ulaştığı düşünülmektedir. ${ }^{[16]}$ Ancak çalışmamızda hastalık süresinin nöbet sıklığı üzerine istatistiksel anlamlı etkisi gösterilememiştir.

VNS implantasyonu sonrası yara yeri enfeksiyonu ve vokal kord paralizisi oldukça seyrek gözlenmekle beraber en sık rastlanan komplikasyonlardır. ${ }^{[19]} \mathrm{Bu}$ çalışmadaki hasta grubunda cerrahi sonrası önemli bir komplikasyon yaşanmamıştır. Kawai ve arkadaşlarının yaptığı bir çalışmada hastaların \%11.2'sinde stimulasyonun başlaması ile ses kısıklığı ve öksürüğün gözlendiği ve 1. yıl takiplerinde hastaların sadece \%2.5'inde bu bulguların devam ettiği gözlenmiştir. [14] Çalışmamızda, stimulasyonunun başlamasıyla öksürük ve ses kısıklığı hastaların tamamında yaşanmış, ancak sonrasında düzelmiştir.

Dahil edilen hasta sayısının az olması, hastaların nöbet şiddetlerindeki değişikliklerinin dökümente edilmemesi, yaşam kalitelerinin değerlendirilmemiş olması ve kısa takip süresi çalışmamızın zayıf yönlerini oluşturmaktadır. 
Sonuç olarak; literatürdeki pek çok çalışma ile uyumlu olarak bu çalışmada da VNS'in, hastaların yaklaşık \%50'sinde nöbet sıklığında azalma yarattığı gösterilmiştir. Her ne kadar kumulatif bir etkisinden bahsedilse de bu çalışmada, gerek örneklemin küçük olması gerekse takip süresinin kısa olması nedeniyle böyle bir sonuca varılamamıştır. Sonuç olarak, her ne kadar etki mekanizması halen tam olarak anlaşılamamış olsa da VNS implantasyonunun, rezektif cerrahiye aday olmayan fokal ya da jeneralize dirençli epilepsi hastalarının tedavisinde kullanımının güvenli olduğu düşünülmektedir.

Çalışmamız ile ilişkili herhangi bir çıkar çatışması bulunmamaktadır.

Informed Consent- Due to the retrospective design of the study, informed consent was not taken.

Ethics Committee Approval- Ethics committee approved.

Peer-review- Externally peer-reviewed.

Authorship Contributions- Concept: F.E., G.G., D.A.; Design: F.E., G.G., A.C.D.; Supervision: G.G., D.A.; Data collection \&/or processing: F.E., G.G., Z.B.G., A.C.D.; Analysis and/or interpretation: F.E., Z.B.G., A.C.D.; Literature search: F.E., Z.B.G.; Writing: F.E., G.G., D.A.; Critical review: F.E., G.G., A.C.D.

Conflict of interest- The authors declare that they have no conflict of interest.

Financial Disclosure: The authors declared that this study has received no financial support.

Hasta Onamı- Çalışmanın retrospektif tasarımından dolayı hasta onamı alınamamıştır.

Etik Komite Onayı- Etik kurul onayı alındı.

Hakem Değerlendirmesi- Dış bağımsız.

Yazarlık Katkıları- Konsept: F.E., G.G., D.A.; Dizayn: F.E., G.G., A.C.D.; Kontrol: G.G., D.A.; Veri Toplama veya İşleme: F.E., G.G., Z.B.G., A.C.D.; Analiz ve Yorumlama: F.E., Z.B.G., A.C.D.; Literatür Arama: F.E., Z.B.G.; Yazan: F.E., G.G., D.A.; Kritik Revizyon: F.E., G.G., A.C.D.

\section{Çıkar Çatışması- Yoktur.}

Finansal Destek- Yazarlar bu çalışma için finansal destek almadıklarını beyan etmişlerdir.

\section{Kaynaklar}

1. Kwan P, Arzimanoglou A, Berg AT, Brodie MJ, Allen Hauser W, Mathern $G$, et al. Definition of drug resistant epilepsy: consensus proposal by the ad hoc Task Force of the ILAE Commission on Therapeutic Strategies. Epilepsia 2010;51(6):1069-77. [CrossRef]

2. Kwan P, Schachter SC, Brodie MJ. Drug-resistant epilepsy. N
Engl J Med 2011;365(10):919-26. [CrossRef]

3. Pérez-Carbonell $L$, Faulkner $H$, Higgins $S$, Koutroumanidis $M$, Leschziner $\mathrm{G}$. Vagus nerve stimulation for drug-resistant epilepsy. Pract Neurol 2020;20(3):189-98. [CrossRef]

4. Englot DJ, Ouyang D, Garcia PA, Barbaro NM, Chang EF. Epilepsy surgery trends in the United States, 1990-2008. Neurology 2012;78(16):1200-6. [CrossRef]

5. Morris GL 3rd, Gloss D, Buchhalter J, Mack KJ, Nickels K, Harden C. Evidence-based guideline update: vagus nerve stimulation for the treatment of epilepsy: report of the Guideline Development Subcommittee of the American Academy of Neurology. Neurology 2013;81(16):1453-9. [CrossRef]

6. Bek S, Erdoğan E, Gokcil Z. Vagal sinir stimulasyonu ve hasta seçimi. Epilepsi 2012;18(Suppl 1):63-7.

7. Ben-Menachem E, Hamberger A, Hedner T, Hammond EJ, Uthman BM, Slater J, et al. Effects of vagus nerve stimulation on amino acids and other metabolites in the CSF of patients with partial seizures. Epilepsy Res 1995;20(3):221-7. [CrossRef]

8. Majoie HJ, Rijkers K, Berfelo MW, Hulsman JA, Myint A, Schwarz $M$, et al. Vagus nerve stimulation in refractory epilepsy: effects on pro- and anti-inflammatory cytokines in peripheral blood. Neuroimmunomodulation 2011;18(1):52-6. [CrossRef]

9. McHugh JC, Singh HW, Phillips J, Murphy K, Doherty CP, Delanty $\mathrm{N}$. Outcome measurement after vagal nerve stimulation therapy: proposal of a new classification. Epilepsia 2007;48(2):375-8.

10. Morace R, Di Gennaro G, Quarato PP, D'Aniello A, Mascia A, Grammaldo $L$, et al. Vagal Nerve Stimulation for Drug-Resistant Epilepsy: Adverse Events and Outcome in a Series of Patients with Long-Term Follow-Up. Acta Neurochir Suppl 2017;124:49-52. [CrossRef]

11. Elliott RE, Rodgers SD, Bassani L, Morsi A, Geller EB, Carlson C, et al. Vagus nerve stimulation for children with treatment-resistant epilepsy: a consecutive series of 141 cases. J Neurosurg Pediatr 2011;7(5):491-500. [CrossRef]

12. Pakdaman $H$, Amini Harandi A, Abbasi M, Karimi M, Arami MA Mosavi SA, et al. Vagus nerve stimulation in drug-resistant epilepsy: the efficacy and adverse effects in a 5-year follow-up study in Iran. Neurol Sci 2016;37(11):1773-8. [CrossRef]

13. Englot DJ, Chang EF, Auguste KI. Vagus nerve stimulation for epilepsy: a meta-analysis of efficacy and predictors of response. J Neurosurg 2011;115(6):1248-55. [CrossRef]

14. Kawai K, Tanaka T, Baba H, Bunker M, Ikeda A, Inoue Y, et al. Outcome of vagus nerve stimulation for drug-resistant epilepsy: the first three years of a prospective Japanese registry. Epileptic Disord 2017;19(3):327-38. [CrossRef]

15. Nalbantoglu M, Ozkara C, Yeni N, Demirbilek V, Yalcınkaya C, Delil $S$, et al. Efficacy of vagus nerve stimulation in patients with drug resistant epilepsy. Epilepsi 2014;20(1):23-8. [CrossRef]

16. Englot DJ, Chang EF, Auguste KI. Efficacy of vagus nerve stimulation for epilepsy by patient age, epilepsy duration, and seizure type. Neurosurg Clin N Am 2011;22(4):443-8. [CrossRef]

17. Wheless JW, Gienapp AJ, Ryvlin P. Vagus nerve stimulation (VNS) therapy update. Epilepsy Behav 2018;88S:2-10. [CrossRef] 
18. Helmers SL, Wheless JW, Frost M, Gates J, Levisohn P, Tardo C, et al. Vagus nerve stimulation therapy in pediatric patients with refractory epilepsy: retrospective study. J Child Neurol 2001;16(11):843-8. [CrossRef]
19. Selner AN, Rosinski CL, Chiu RG, Rosenberg D, Chaker AN, Drammeh $\mathrm{H}$, et al. Vagal Nerve Stimulation for Epilepsy in Adults: A Database Risk Analysis and Review of the Literature. World Neurosurg 2019;121:e947-53. [CrossRef] 